\title{
The Enlargement of the Suez Canal and Introduction of Non-Indigenous Species to the Mediterranean Sea
}

\section{Bella Galil, Ferdinando Boero, Simona Fraschetti, Stefano Piraino, Marnie Campbell, Chad Hewitt, James Carlton, Elizabetb Cook, Anders Jelmert, Enrique Macpherson, Agnese Marchini, Anna Occhipinti-Ambrogi, Cyntbia Mckenzie, Dan Minchin, Henn Ojaveer, Sergej Olenin, and Greg Ruiz}

The Suez Canal is one of the most important waterways in the world - during the last year 17,148 ships passed through the Canal - reducing emissions, saving time, and operating costs to shippers. The rapid increase in ship size from the "Post-Suezmax" (> 12,000 TEU) to the latest container vessels (> 19,000 TEU) now requires enlargements of port facilities and canals.

A project of this magnitude, and with potentially negative environmental outcomes, requires a transparent and scientifically sound "Environmental Impact Assessment” (EIA). An explicit obligation on Parties to the Convention on Biological Diversity (https://www.cbd.int/doc/ legal/cbd-en.pdf) was made to consider transboundary impacts on biodiversity, particularly those associated with invasive non-indigenous species. Although a nonbinding instrument, the "Rio Declaration on Environment and Development" sets forth important principles of international environmental law (UN 1992): States are responsible for ensuring that activities within their jurisdiction do not damage the environment of other States, and EIA, as a national instrument, shall be undertaken for proposed activities that are likely to have a significant adverse impact on the environment. To our knowledge, no Environmental Impact Assessment has been

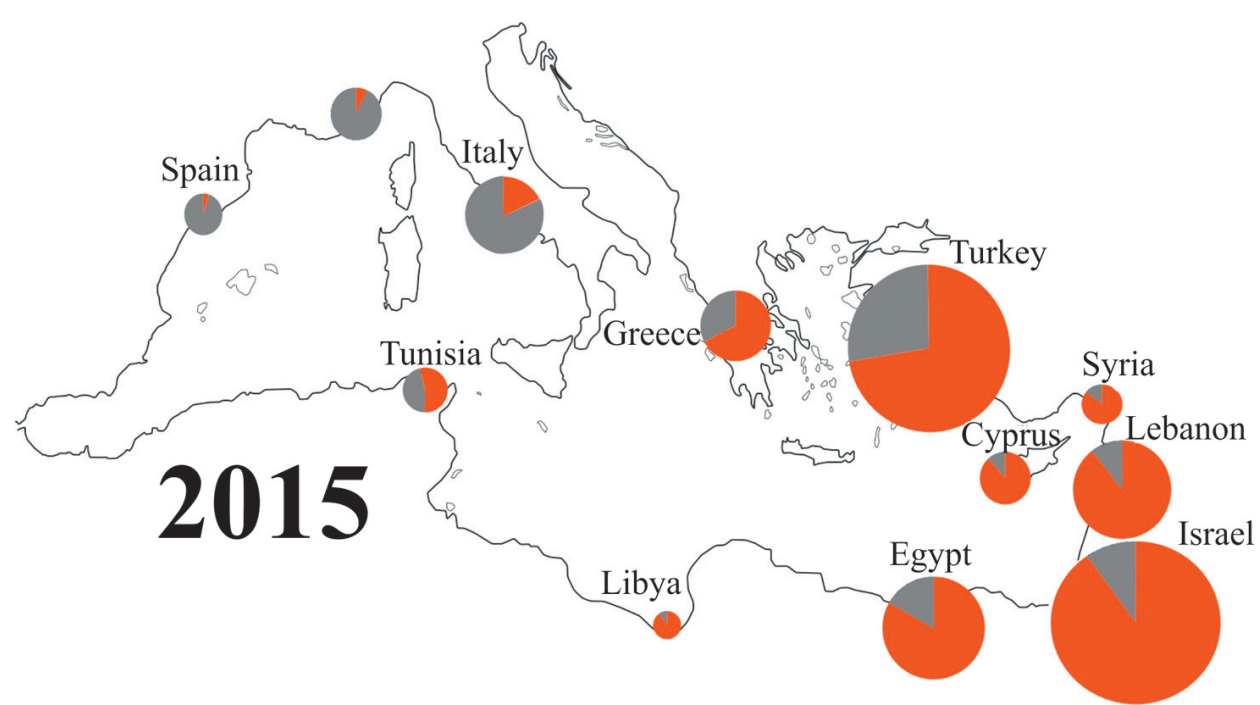

Fig. 1. The number of nonindigenous species in some Mediterranean countries. In red, the fraction of species likely introduced through the Suez Canal.

This article was published online 12 May 2015. Subsequently, it was determined that the article sequence

within the issue was incorrect and the correction was published online on 6 June 2015. 
made available for public view, should it exist.

We are particularly concerned about the possibility that the enlargement will facilitate further introduction of Red Sea species into the Mediterranean Sea. To-date, 443 species of macrophytes, invertebrates and fish are likely to have entered the Mediterranean Sea through the Suez Canal, of which number 89 have been recorded in five or more countries. Some of these species have had significant impacts. A scyphozoan jellyfish, Rhopilema nomadica, recorded since the early 1980s, forms huge swarms each summer along the Levantine coast, which adversely affecting tourism, fisheries and coastal installations. The "silverside" pufferfish, Lagocephalus sceleratus, was likely introduced through the Canal to the eastern Mediterranean in 2003 and has recently spread from the Black Sea to Spain. This species poses severe health hazards because its internal organs contain a strong paralytic neurotoxin, inducing vomiting, respiratory arrest, seizures, coma, and occasionally, death. It also damages fishing nets and lines causing economic losses for fishermen. Finally, two herbivorous rabbit fishes, Siganus luridus and S. rivulatus, are responsible for an extraordinary shift in the Levantine Basin from well-developed algal assemblages in the rocky infralittoral to extensive "barrens," with a dramatic decline in biogenic habitat complexity, biodiversity and biomass.

Similarly, Article 4.3(d) of the Regional Sea Convention - the Convention for the Protection of the Marine Environment and the Coastal Region of the Mediterranean ("Barcelona Convention") promotes "cooperation between and among States in environmental impact assessment procedures related to activities under their jurisdiction or control which are likely to have a significant adverse effect on the marine environment of other States or areas beyond the limits of national jurisdiction." Egypt is a signatory to both conventions.

We acknowledge the important role of the Suez Canal in global trade; however, we are concerned about the inattention to international agreements and the neglect of sustainable practices that might be employed to minimize deleterious environmental impacts with long term consequences. EIA is a scientifically valid, formal process to identify potential adverse effects as a consequence of planned activities, both

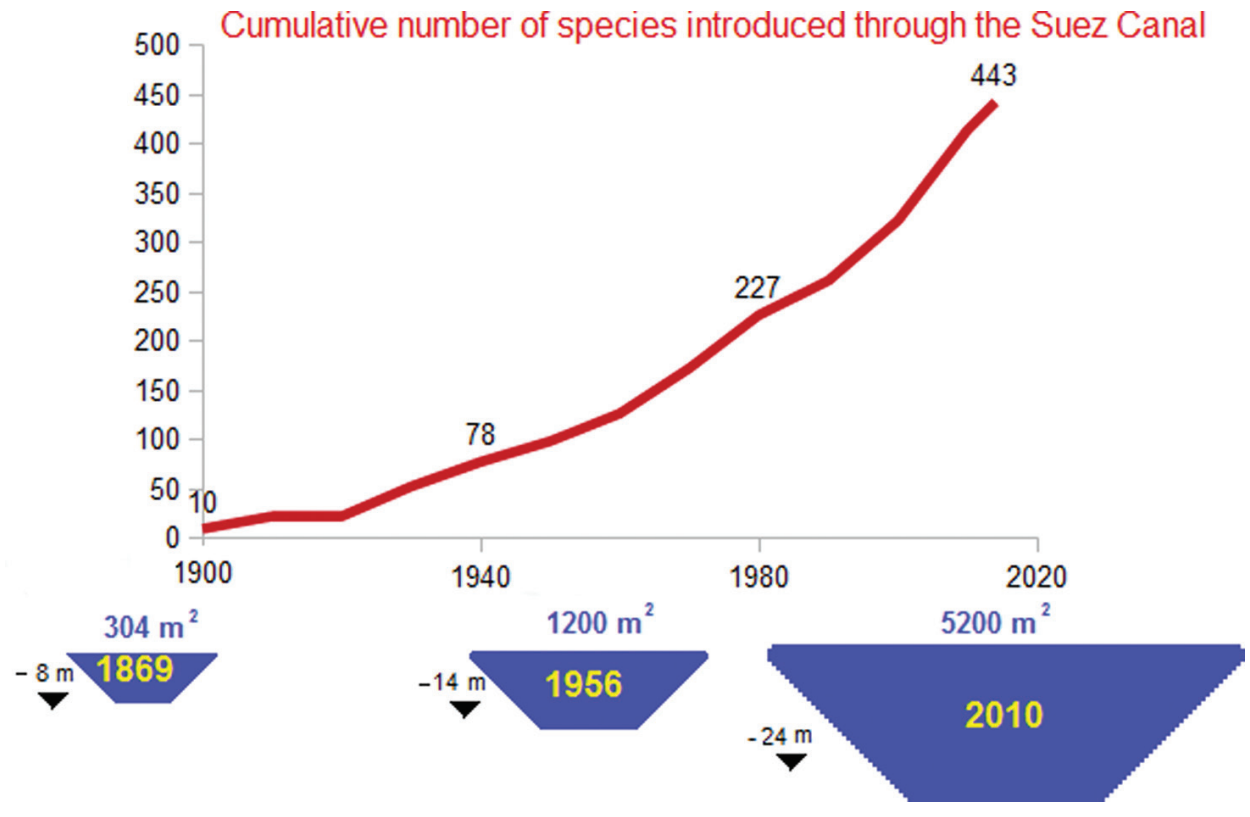

Fig. 2. Cumulative number of species thought to be introduced through the Suez Canal to the Mediterranean sea.

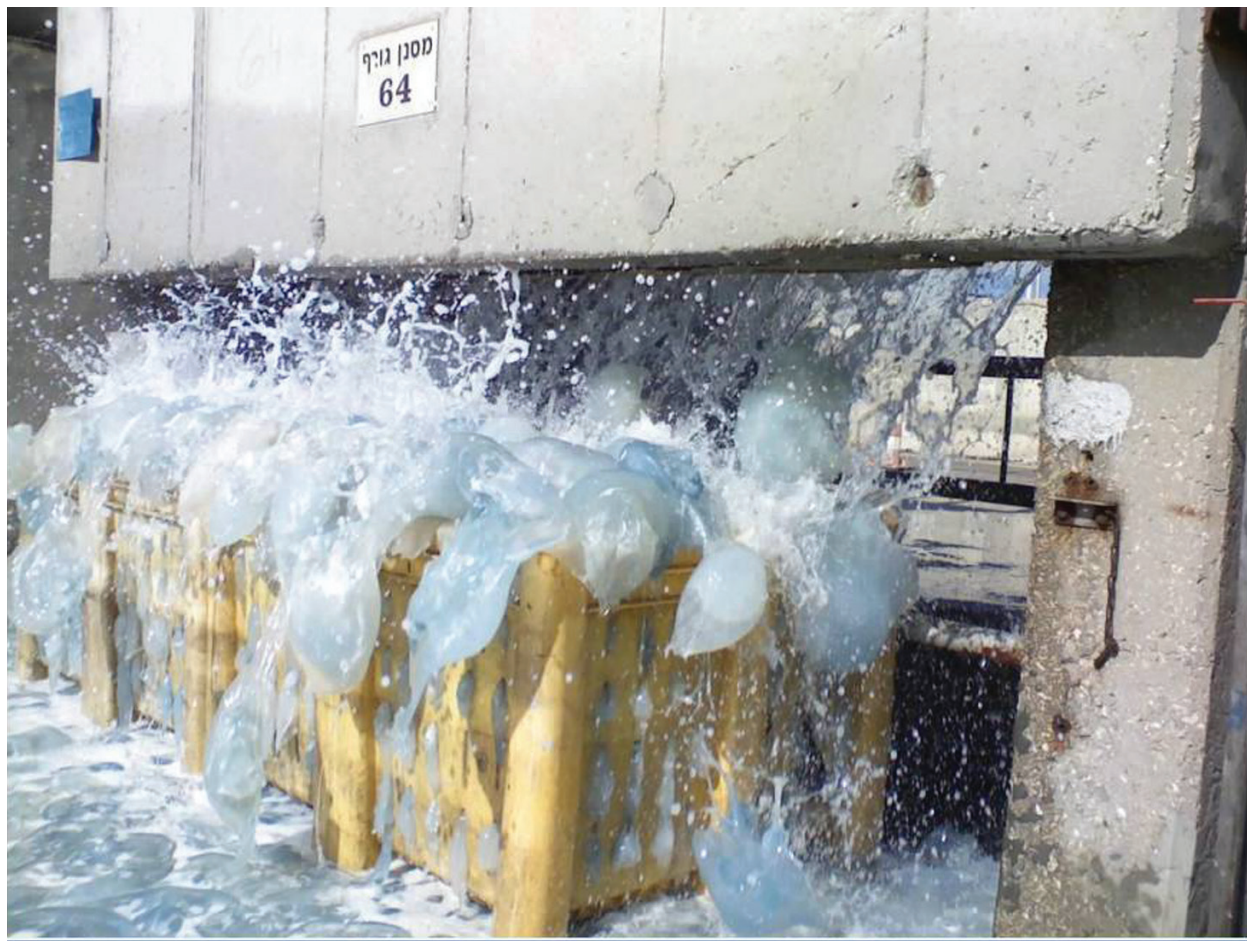

Fig. 3. A swarm of the scyphozoan jellyfish, Rhopilema nomadica, likely introduced through the Suez Canal, blocked water-intake pipes of power plant in Israel, 2011.

during the development and operational phases of a project. An EIA would facilitate evaluation of and choices for the implementation of cost-effective mitigating strategies and infrastructure.

We are writing as concerned scientists, whose research deals with the effects of unrestrained introduction of invasive non-indigenous species.
This is one opportunity to prevent, or minimise, a potential great ecological setback to the biodiversity and the ecosystem of the Mediterranean Sea that should not be missed. We have already expressed our concerns in open letters, signed by scientists from 39 countries, sent to the intergovernmental organizations and to the appropriate EC Commissioners. 


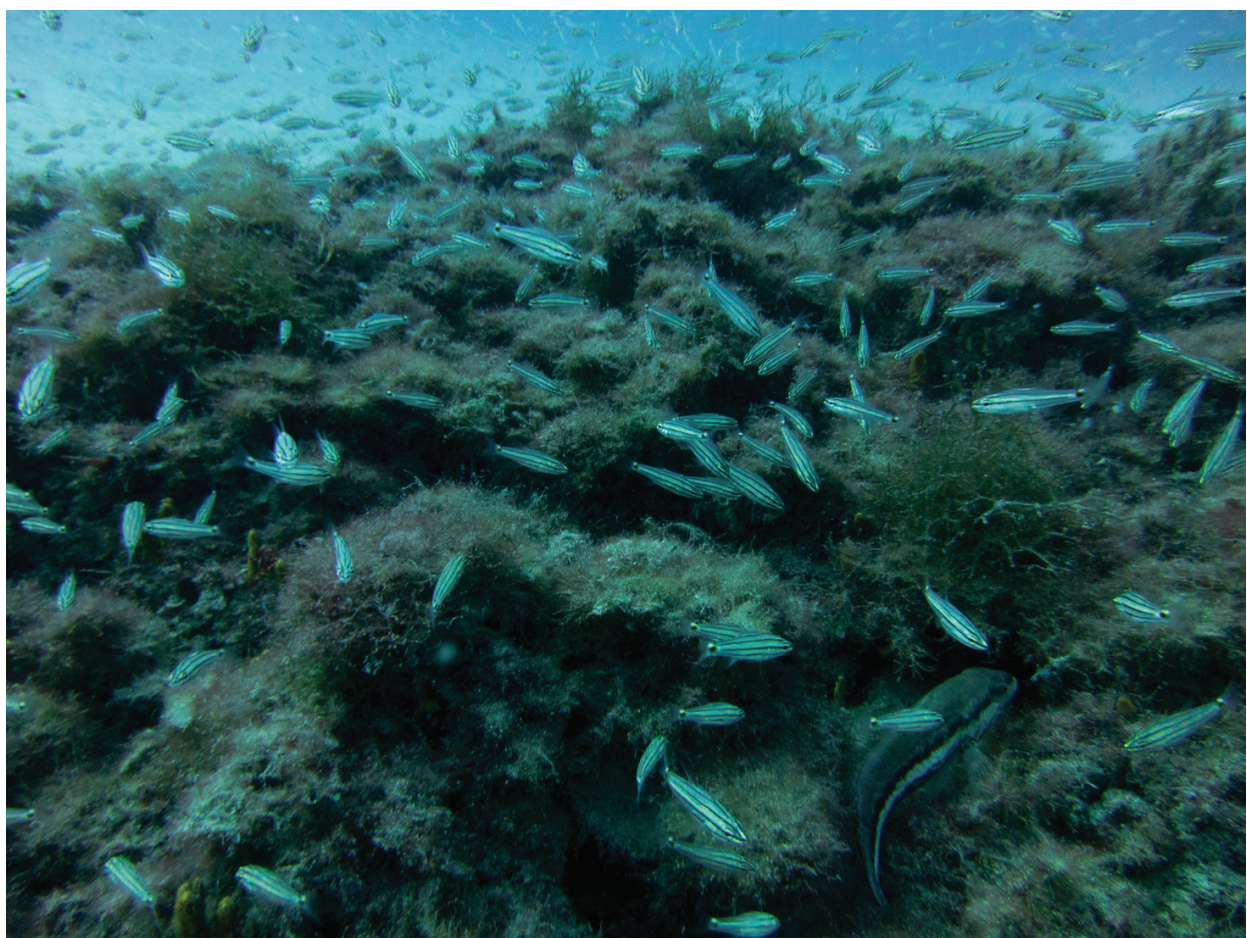

Fig. 4. A school of the twospot cardinalfish, Cheilodipterus novemstriatus at Rosh HaNikra canyon, Israel, 2012. The species was first recorded off Israel in 2010 (Photo: B.S. Rothman).

There is still much more that can be done we invite you to join us. If you agree, please send a brief email with your name and affiliation to bella@ocean.org.il

\section{Reference}

UN (1992). Report of the United Nations Conference on Environment and Development. Rio de Janeiro 3-14 June 1992. A/CONF.151/26 (Vol. I).
Bella Galil, National Institute of Oceanography, Israel Oceanographic and Limnological Research, Haifa, Israel, bella@ocean.org.il

Stefano Piraino, Simona Fraschetti, Ferdinando Boero, Department of Biological and Environmental Science and Technologies, University of Salento, Lecce, Italy, ferdinando.boero@unisalento. it, simona.fraschetti@unisalento.it, stefano. piraino@unisalento.it
Chad Hewitt, Marnie Campbell, School of Science, University of Waikato, Hamilton, New Zealand, mcampbel@waikato.ac.nz, chewitt@waikato.ac.nz

James Carlton, Maritime Studies Program, Williams College-Mystic Seaport, Mystic, CT, USA, James.T.Carlton@williams.edu

Elizabeth Cook, Scottish Marine Institute, Oban, Argyll, UK, Elizabeth.Cook@sams.ac.uk

Anders Jelmert, Flødevigen Marine Research Station, Institute of Marine Research, His Norway, anders.jelmert@imr.no

Enrique Macpherson, Centro de Estudios Avanzados de Blanes (CSIC), Blanes Girona, Spain,macpherson@ceab.csic.es

Anna Occhipinti-Ambrogi, Agnese Marchini, Department of Earth and Environmental Sciences, University of Pavia, Pavia, Italy, agnese.marchini@ unipv.itocchipin@unipv.it

Cynthia Mckenzie, Northwest Atlantic Fisheries Centre, St. John's, NL, Canada, Cynthia.Mckenzie@ dfo-mpo.gc.ca

Dan Minchin, Marine Organism Investigations, 3 Marina Village, Ballina Killaloe, Co Clare, Irelandmoiireland@yahoo.ie

Henn Ojaveer, Estonian Marine Institute, University of Tartu, Pärnu, Estonia, henn.ojaveer@ut.ee

Sergej Olenin, Coastal Research and Planning Institute, Klaipeda University, Klaipeda, Lithuania, sergej@corpi.ku.lt

Greg Ruiz, Smithsonian Environmental Research Center, Edgewater, MD, USA, ruizg@si.edu 